\title{
Myosin 1g and 1f: A Prospective Analysis in NK Cell Functions
}

\author{
David Cruz-Zárate ${ }^{1,2 \dagger}$, Carlos Emilio Miguel-Rodríguez ${ }^{1,3 \dagger}$, \\ Irving Ulises Martínez-Vargas ${ }^{1,3}$ and Leopoldo Santos-Argumedo ${ }^{1 *}$ \\ 1 Departamento de Biomedicina Molecular, Centro de Investigación y de Estudios Avanzados del Instituto Politécnico \\ Nacional, Ciudad de México, Mexico, 2 Departamento de Inmunología, Escuela Nacional de Ciencias Biológicas, \\ Instituto Politécnico Nacional, Ciudad de México, Mexico, ${ }^{3}$ Departamento de Infectómica y Patogénesis Molecular, \\ Centro de Investigación y de Estudios Avanzados del Instituto Politécnico Nacional, Ciudad de México, Mexico
}

NK cells are contained in the ILC1 group; they are recognized for their antiviral and antitumor cytotoxic capacity; NK cells also participate in other immune response processes through cytokines secretion. However, the mechanisms that regulate these functions are poorly understood since NK cells are not as abundant as other lymphocytes, which has made them difficult to study. Using public databases, we identified that NK cells express mRNA encoding class I myosins, among which Myosin $1 \mathrm{~g}$ and Myosin $1 \mathrm{f}$ are prominent. Therefore, this mini-review aims to generate a model of the probable participation of Myosin $1 \mathrm{~g}$ and $1 \mathrm{f}$ in NK cells, based on information reported about the function of these myosins in other leukocytes.

Keywords: Class I Myosin, NK cell, Myo1g, Myo1f, cytoskeleton

\section{INTRODUCTION}

Innate lymphoid cells (ILCs) neither express $\mathrm{T}$ and B lymphocyte receptors but are derived from common lymphoid progenitors (CLPs) $(1,2)$. There is evidence about the capacity of ILC2 and ILC3 needed to recognize and present antigen to $\mathrm{T}$ lymphocytes and, in this way, maintain immune homeostasis (3-6). ILCs have been considered the innate equivalent of T helper lymphocytes (Th), Th1, Th2, and Th17 since ILC releases the same cytokine profile of Th cell (7-10). ILCs can mirror even T regs functions due to their capacity to produce TGF- $\beta$ and IL-10 (11-13). NK cells belong to the ILC1 group (14). They are crucial in antiviral and antitumor response through their cytotoxic activity $(15,16)$. NK cells require the optimal function of the actin cytoskeleton and cellular membrane dynamics to perform their functions. In NK cells, the actin cytoskeleton reorganization is achieved by activation signals through several activation receptors, such as; Killer-cell Immunoglobulin-like Receptor (KIR), Natural Cytotoxicity Receptor (NCR), CD16, Signaling Lymphocyte Activation Molecule (SLAM), and others $(17,18)$. In a reductionist model, CD16, NKp46, NKp30 receptors associate with adapter proteins with Immunoreceptor Tyrosine-based Activation (ITAM) domains such as CD3 $\zeta$, FcERI $\gamma$; whereas NKp44 associate with DAP12. Src kinase family members phosphorylate tyrosines in the ITAMs. Phosphorylated ITAMs form a binding site for the Src homology 2 (SH2) domains of the ZAP70 and SYK tyrosine kinase, which induce SLP-76 phosphorylation. Vav1 then recognizes phosphorylated SLP-76 via SH2 domain (19, 20). Next, SLAM family receptors transmit activation signals through the SLAM-Associated Protein 
(SAP), which recruits tyrosine kinase (Fyn) (21). Then Fyn induces Vav1 phosphorylation (22). ITAM independent signaling through the NKG2D receptor also induces Vav1 recruitment via PI3K and Grb2 after DAP10 tyrosine phosphorylation (23-26). In this way, Vav1 has an essential role in NK cell function. Vav1-deficient NK cells show defects in tumor cell killing (27). A synergistic effect is required to achieve ubiquitin ligase c-Cbl inhibition, which controls the availability by Vav1 (28). Consequently, Vav1 regulates actin cytoskeleton polymerization by activating the GTPases Rac, Rho, and Cdc42 since Vav1 has GEF properties (29). In this dynamic process, myosins participate at different levels, either during the polarization or aggregation of integrins, maintaining membrane tension, or interacting directly with other proteins.

NK cells are not abundant as other lymphocytes; this scarcity hinders the analysis of NK functions. Searching in databases and the analysis of the mechanisms reported in other similar cells could help understand NK lymphocytes that eventually will lead to a broader perspective about the function of these cells.

\section{OVERVIEW OF NK CELLS}

Natural Killer cells are innate lymphocytes (ILC1s) known primarily for their antiviral and antitumor cytotoxic capacity $(16,30)$. However, they also have effector functions such as releasing cytokines, such as IFN- $\gamma$, TNF- $\alpha$, IL-10, and others (8, 10, 31). Thus, NK lymphocytes are considered part of the sentinels of the innate immune system. In humans, two populations of NK cells have been described, $\mathrm{CD} 56{ }^{\mathrm{dim}} \mathrm{CD} 16^{+}$ and $\mathrm{CD} 56^{\text {bright }} \mathrm{CD} 16^{\mathrm{dim}}(32,33)$. There are differences between both populations; for example, $\mathrm{CD} 56{ }^{\mathrm{dim}} \mathrm{CD} 16^{+}$has more cytotoxic capacity than $\mathrm{CD} 56^{\text {bright }} \mathrm{CD} 16^{\mathrm{dim}}$ or $\mathrm{CD} 16^{\text {. }}$.

In contrast, upon monocytes-derived-stimuli, the CD56 bright CD16 ${ }^{\mathrm{dim} /-}$ NK lymphocytes release a high amount of cytokines $(7,32,33)$. Thus, $\mathrm{CD} 56^{-} \mathrm{CD} 16^{+}$subpopulation is usually found in HIV-infected individuals presenting the high expression of NK inhibitory receptors, associated with poor cytotoxic activity (34). Regarding their anatomical distribution, the presence of NK cells has been observed in both lymphoid and non-lymphoid tissues (7). The cytotoxic activity of NK lymphocytes depends on their ability to release preformed cytotoxic granules contained in vesicles (35). The exocytosis of lytic granules begins with the contact between NK lymphocyte and target cells, which gives rise to the cytotoxic synapse (36-38).

Furthermore, NK cells express on their surface receptors of the TNF family, such as FasL and TRAIL, which can induce apoptosis by binding to their Fas or TRAIL ligand, respectively (37). Thus, the regulation of NK cell functions depends on the balance between activation and inhibition signals given by receptors present on their membrane (35). Within the group of inhibitory receptors, one can find the KIRs in humans and Ly49 Isoforms (A, B, C, E, G, Q) in mice. These receptors inhibit, inside-out and outside-in, LFA-1 signaling at different levels, preventing polarization and degranulation $(39,40)$. Therefore, a decrease in MHC-I expression reduces the inhibitory signal and promotes the activation of the NK cell. Additionally, in both humans and mice, the CD94/NKG2A heterodimer recognizes non-classical MHC-I molecules in the context of HLA-E (human) or H2-Qa1 (mouse). The ligands of the activating receptor NKG2D are represented by MICA/B and by ULBP in humans, and Mult1 and Rae1 in mouse $(7,10,41)$.

On the other hand, activation signals are given by activation receptors, for example, Ly49 (D, H, L) and KIR isoforms, NKG2D, and natural cytotoxic receptors such as NKp30 and NKp44 in humans and NKp46 in humans and mice $(7,10)$. Additionally, LFA-1, $\beta 1$, and $\beta 2$ integrins can also regulate NK cell function (42), which we will address later. Signaling of activation and inhibition receptors regulate several NK cells functions, for example, degranulation, morphological modifications to increase NK-target cell contacts, cell migration, and cytokine release. Since Myolg and Myolf are involved in morphological changes and vesicular traffic, studying these proteins in the NK cell physiology becomes relevant (43). Thus, the functions of NK lymphocytes are dynamic processes that may be regulated by cytoskeletal proteins such as myosins.

Furthermore, there are functional differences among NK cell subpopulations depending on their anatomical distribution (44). For example, IL-12- and IL-18-induced IFN- $\gamma$ production varies between mouse $\mathrm{CD} 27^{\text {high }}$ spleen-resident and $\mathrm{CD} 27^{\text {low }}$ lungresident NK cells (32). In humans, NK CD56 ${ }^{\text {bright }}$ under in vitro stimulation of IL-12 and IL-18 induce the release of more IFN- $\gamma$ and TNF- $\beta$ than NK CD56 ${ }^{\mathrm{dim}}$ cell (45). Therefore, a detailed understanding of the intrinsic factors regulating NK cell functions could provide tools to modulate any particular function depending on the type of required response.

\section{CLASS I MYOSINS}

Myosins are a family of motor proteins, which are mainly known for their function in cell contractility. However, some members of this family proteins, for example, Myosin V, VI, and Ic participate in moving different cargos along the actin filaments, such as vesicles, mitochondria, and ribonuclear protein particles (46-51). Currently, 35 classes of myosins have been reported in eukaryotic organisms (52). This classification varies depending on the species; for example, 12 classes of myosin's are described in humans (53-55). Class I myosins are non-filamentous myosins, consisting of one heavy chain and a variable number of light chains (56). The heavy chain contains three conserved regions; the ATP-dependent globular or motor domain, which binds to F-actin $(57,58)$. Adjacent to the motor domain is the neck region, where light chains associate and regulate the globular domain (57). In addition, the neck region has IQ domains, sequences that interact with calmodulin and calmodulin-like chains (57). Finally, the tail variable section bestows different functions depending on the domains present in that region $(50,51,54,56,57)$. Class I myosins are subdivided into short-tailed and long-tailed myosins; both have a Pleckstrin homology domain inside the TH1 domain, as shown in Figure 1A, which allows interaction with several phospholipids 
present in the membrane and other compartments in a $\mathrm{PH}-$ dependent manner $(51,59)$. Long-tailed myosins have two additional domains; a proline-rich domain (TH2) and a domain homologous to SRC kinase (SH3) (50, 51, 56, 60). Humans and mice have a total of 8 genes coding for six shorttailed myosins (Myola, b, $c, d, g$, and $h$ ) and two long-tailed myosins (Myole, f) (58). Remarkably, only Myolc, d, e, f, and g have been described in leukocytes $(51,60)$. Myolg has a length of 1018 amino acids in humans and 1024 amino acids in mice (https://www.uniprot.org/) and belongs to the group of shorttailed myosins. It has a $\mathrm{PH}$-type domain in the tail region, which allows its binding to lipids in the plasma membrane and microdomains rich in phospholipids and cholesterol, known as lipid rafts $(59,61,62)$. The expression of Myolg has been observed mainly in $\mathrm{T}$ and $\mathrm{B}$ lymphocytes and mast cells (6365). Myolg has been proposed as a bridge that allows the adequate interaction between the membrane and the cytoskeleton in processes such as cytokine secretion, cell migration, mobilization, recycling of membrane molecules, and regulating modifications in the cytoskeleton that favor cell adhesion $(63,65,66)$.

On the other hand, Myolf has a length of 1098 amino acids in humans and 1099 amino acids in mice (https://www.uniprot.org/). Its expression has been confirmed in neutrophils, macrophages, mast cells, and T lymphocytes (67-71). Similar to Myolg, Myolf is located adjacent to the plasma membrane, co-localizing with cortical actin and interacting with membrane phosphoinositides (67). As mentioned above, Myolf has two additional domains, a $\mathrm{TH} 2$ and an $\mathrm{SH} 3$ that allows the interaction with several proteins. In addition, it has been observed that Myolf interacts with 3BP2 (69), activating Cdc42 (72) suggesting a Vav1 pathway that potentially activates Rac and RhoA (73), thus regulating the cytoskeletal machinery to favor morphological changes and the generation of membrane protrusions.

As shown in Figure 1B, some class I myosins' mRNAs are expressed by NK cells (74). However, it will be necessary to prove this expression at a protein level. The presence of Myosin $1 \mathrm{~g}$ (Myolg) and Myosin 1f (Myolf) mRNA occur from the early stages of NK cell development (https://gexc.riken.jp). Likewise, human peripheral blood NK cells also show high Myolg and Myolf mRNA (75-77) (https://www.proteinatlas.org). Interestingly, tumor resident ILC1 and NK cells also express Myolg and Myolf (78). These results suggest that both mouse and human NK cells express both myosins and that the expression is maintained in the context of their antitumor effect. Therefore, it would be essential to analyze the role of these myosins in NK-cell differentiation, development, and functions. Class I myosins reported in leukocytes regulate processes requiring the interaction between the plasma membrane and actin cytoskeleton, such as cytokines secretion, cell migration, and mobilization of plasma

A

\begin{tabular}{l|l|l|l|l|l|l|l|l} 
Myo1g & Motor & IQ & PH TH1 & $\begin{array}{l}\text { Human } 1018 \text { aa } \\
\text { Mouse } 1024 \text { aa }\end{array}$
\end{tabular}

\begin{tabular}{|c|c|c|c|c|c|c|}
\hline Myo1f & Motor & IQ & PH TH1 & TH2 & SH3 & $\begin{array}{l}\text { Human } 1098 \text { aa } \\
\text { Mouse } 1099 \text { aa }\end{array}$ \\
\hline & Motor & & & Tail & & \\
\hline
\end{tabular}

B

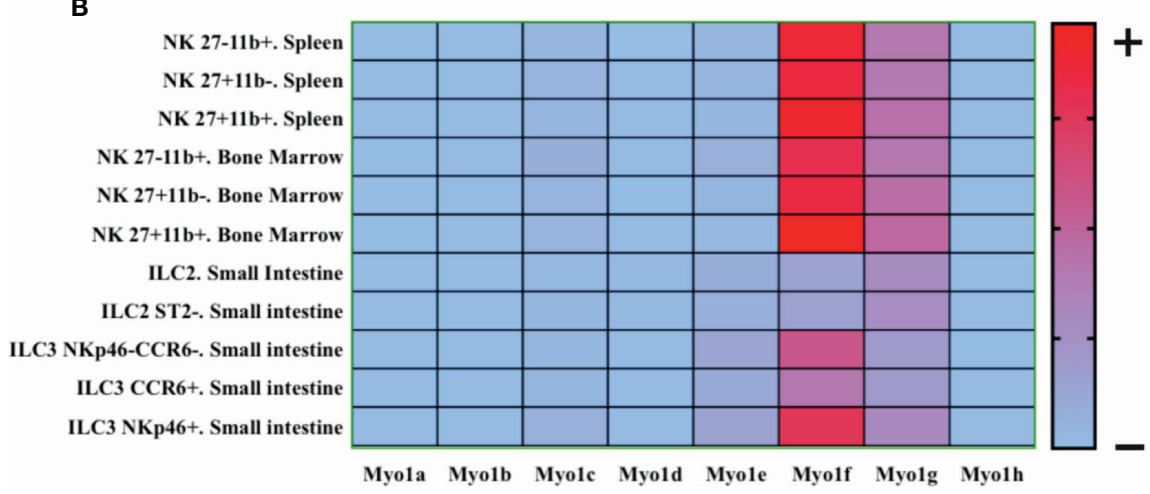

FIGURE 1 | Schematic representation of Myo1g and Myo1f structure and heat map of expression of class I myosin in innate lymphoid cells. (A) Myo1g has a sequence of 1018 amino acids (human) and 1024 amino acids (mouse), while Myo1f has a sequence of 1098 amino acids (human) and 1099 amino acids (mouse). In addition, both myosins have a motor domain in the amino-terminal region, following a neck region with an IQ domain and a TH1 domain in the tail region which allows phosphoinositide interaction in a PH-manner dependent. Finally, Myo1f had two additional domains: TH2 (a proline-rich region) and SH3 (a proline-rich-interacting region), allowing protein-proteins interactions. Created with BioRender.com. (B) Class I Myosin expression in ILCs was explored with data from: http://www.immgen.org. The heat map was generated using GraphPad Prism version 8.0.0 for Mac OS X, GraphPad Software, San Diego, California USA, www.graphpad.com. 
membrane molecules. Therefore, we aim to analyze class I myosins' participation in NKs functions, using information derived from results published in other leukocytes.

\section{MY01G AND MY01F COULD REGULATE CYTOTOXIC SYNAPSE THROUGH MORPHOLOGICAL CHANGES}

Cytotoxicity is one of the main functions depending on morphological changes regulated by the cytoskeleton. The cytotoxic activity of NK lymphocytes first requires interaction with their target through a cytotoxic synapse and subsequently the release of cytotoxic granules towards the target cell (79). The synapse is dependent on the mobilization of different surface molecules such as adhesion molecules and integrins (80). First, the synapse requires close contact with the target cell by generating projections (filopodia and lamellipodia), this depends on the force generated by the myosins (81). The formation of these protuberances depends on Cdc 42 and RhoA (29). Physical properties such as membrane tension allow membrane deformation to generate these projections $(81,82)$. Myolg is abundantly expressed in the protuberances generated by B lymphocytes (63).

On the other hand, B lymphocytes show reduced membrane tension in its absence, decreasing their ability to generate filopodia and lamellipodia (83). Besides, Myolf siRNA-treated macrophages decrease their capacity to generate morphological changes (84). In this way, Myolg and Myolf could participate in the early stages of the cytotoxic synapse of the NK cell, regulating the formation of membrane protrusions that allow interaction with their target cell.

\section{PROBABLE PARTICIPATION OF MYO1G AND MYO1F IN NK CELL MIGRATION}

Cell migration depends on cytoskeleton changes that promotes the interaction of migrating cells with the endothelium. There is evidence showing that class I myosins regulate the expression of the molecules during leukocyte migration $(65-67,85)$. NK cells are recruited to different tissue compartments, i.e., lymph nodes and inflamed tissues, where they perform different functions such as promoting DC maturation, $\mathrm{T}$ cell polarization, and as cytotoxic effector cells $(86,87)$. NK cells express $\beta 1, \beta 2$, and $\beta 7$ integrins, PSGL-1, CD62L, and various chemokine receptors such as CXCR1, CXCR2, CXCR4, CCR5 y CCR7, which allow their interaction with HEV during lymph nodes $(86,88,89)$. NK subpopulations in humans and mice show differences in the expression levels of integrins and adhesion molecules (86). Therefore, the mechanisms by which NK cells migrate to different anatomical sites are not yet fully understood. Selectins and integrins regulate the interaction between the cell and the endothelium, so the expression of these molecules and their mobilization is essential during cell migration. Myolg-deficient
B lymphocytes have reduced adhesion to the endothelium due to a lower expression of LFA-1, CD62L and, VLA-4 (65).

Moreover, in the absence of Myo1g, B lymphocytes have a lower capacity for CXCL13-dependent transmigration to the inguinal node, furthermore in vitro CXCL12-dependent migration is also reduced (65). Migration defects were attributed to a decrease in the expression of adhesion molecules and a lower capacity to generate morphological changes due to the absence of Myolg. Myolfdeficient mice showed a reduction in the recruitment of neutrophils in a lung damage model (68). These neutrophils did not present defects in rolling and adhesion but in extravasation in vivo, explained by inefficient nucleus deformation during migration (68). In vitro CXCL1-dependent chemotaxis was also affected (68). Although it has not been observed that Myolf participates directly in cell migration, it has been seen that Myolf affects the expression of integrins $\beta 1$ and $\beta 7$ in mast cells (72).

Additionally, in mast cells, the activation of phosphatidylinositol 3-kinase (PI3K) increases $\mathrm{PI}(3,4,5) \mathrm{P} 3$, causing the recruitment and association of 3BP2 with Myolf during KIT activation (69). Although the consequence of the interaction of both proteins in other cell types has not been evaluated, in mast cells, 3BP2 participates in different processes; such as degranulation, by regulating the SYK, LAT, and PLC- $\gamma$ pathway; in survival, by regulating the KIT, STAT1, Akt and ERK pathway; and during cell migration, by activating the Cdc42 and Rac2 pathway and regulating the expression of integrin $\beta 1$ (69). Furthermore, $3 \mathrm{BP} 2$ is essential for activating Vavl (73), impacting the activation of GTPases of the Rho family. The absence of Myolf impacts the activation of Cdc42 (72), then its association with 3BP2 could play a role in the activation of Vav1. Consequently, the activation of the GTPases of the Rho family, essential in the polymerization of the actin cytoskeleton, will be affected. RhoA controls the polymerization of cortical actin through its interaction with ROCK1 and ROCK2, forming stress fibers (90). Rac1 and Rac2 are involved in the polymerization of the actin cytoskeleton via the SCAR/WAVE effectors, while Cdc42 controls cell polarity for migration, synapse formation, and cytokine secretion via effectors of the WASP family $(29,91)$. The role played by Myolf, and $1 \mathrm{~g}$ could be crucial for the migration of NK lymphocytes since they could participate by independent mechanisms due to their structural differences.

\section{MY01G AND MY01F REGULATE ADHESION MOLECULES EXPRESSION IN LEUKOCYTES}

Adhesion molecules such as selectins and integrins, in addition to regulating the migration, and increasing the adhesion during cytotoxic synapse, also participate in the activation of NK cells. $\beta 1$ and $\beta 2$ integrins regulate the interaction of the NK cell synapsis, while LFA-1 participates in the polarization of cytotoxic granules and increasing adhesion during synapse (92, 93). As an example of its importance in other lymphocytes, Myo1g-deficient B cells have reduced CD62L and LFA-1 (65). It has been speculated that Myolg participates in the vesicular 
trafficking of these molecules (66). However, no significant differences in LFA-1 expression were found in Myolg-deficient T cells (64). Thus, it is necessary first to evaluate LFA-1 expression and other adhesion molecules in Myolg-deficient NK cells. LFA-1 has acquired notoriety in NK cells because it participates in the activation, adhesion, and regulation of cytotoxic granules (38).

Similarly, Myolf is crucial for the expression of integrins in leukocytes. Myolf-deficient neutrophils increase the expression of $\beta 2$-integrin, which enhances their adherence to ICAM-1 (67). Additionally, macrophage cell lines such as RAW 264.7 and J774, with stable overexpression of Myolf-GFP, have an increased expression of integrin $\alpha \mathrm{V} \beta 3$, leading to increased adhesion vitronectin and promoting an inflammatory phenotype via ILK/ Akt/mTOR activation (70). Silencing Myolf in human mast cells negatively impacts the expression of the integrin $\beta 1$ and $\beta 7$, affecting exocytosis (72). Therefore, the role of Myolf may be highly relevant for the cytotoxicity of NK cells because it is plausible to think that it may regulate the expression of integrins or other membrane molecules essential in NK cell activation.

\section{MY01G AND MY01F COULD REGULATE NK CELL CYTOTOXICITY}

Unlike cytotoxic T lymphocytes, NK cells have performed cytotoxic granules (31). Thus, NK cells have a faster cytotoxic activity, which becomes relevant in viral infections where a quick response is required $(94,95)$. Once the cell recognizes its target, these granules are mobilized to the synapse site by the mTOC (96). Then, these granules fuse with the cell membrane and are released into the pocket of the synapse $(97,98)$. Thus, LFA-1 primarily mediates tight maintenance of the synaptic cleft (92). In this regard, Myolf has been reported to participate during granule mobilization in mast cells through a mechanism dependent on Cdc42 activation (72). However, it has not been evaluated whether Myolg could have a similar function in activating GTPases of the Rho family $(69,72)$.

\section{PARTICIPATION OF MYO1G AND MYO1F IN CYTOKINE PRODUCTION AND RELEASE}

NK cells produce and secrete IFN- $\gamma$ and TNF- $\alpha$ (7). It has been reported that IFN- $\gamma$ production in infections by murine norovirus depends on ISG15 signaling (99-101). The binding of ISG15 to LFA-1 strongly induces the production of IFN- $\gamma$ and IL-10 (99-101). The absence of Myolg decreases LFA-1 expression in B lymphocytes $(63,65)$, suggesting that Myolg could participate in the LFA-1-dependent IFN- $\gamma$ production in the context of viral infections. Cytokines release depends on the fusion of secretory vesicles with the plasma membrane, resulting in the content release towards extracellular space (102). Diverse reports have shown the participation of Myolg and Myolf in releasing TNF- $\alpha$, IL-6, IL-1, lactoferrin, IFN- $\gamma$, and prolactin in B lymphocytes, neutrophils, and mast cells (63, 67, 70, 72). Whether Myolg and Myolf are required for cytokines released by NK cells waits to be determined. However, accumulated evidence with other leukocytes points out in that direction.

\section{MY01G AND MY01F COULD REGULATE OTHER ESSENTIAL NK CELL FUNCTIONS}

Myolg, through its $\mathrm{PH}$ domain, participates in mobilizing and recycling lipid rafts, indirectly moving molecules, such as CD44 $(66,103)$. Lipid rafts from NK cells' membrane are mobilized to the contact site of target cells, but they are excluded in cells resistant to lysis (104). It has been suggested that signaling the KIR2DL1 protein in the cytotoxic synapse inhibits the polarization of the lipid rafts, thus preventing the death of the target cell (104). Given the role of Myolg in mobilizing lipid rafts (66), it is likely that it participates in mobilizing these microdomains during activation and inhibition of NK-cell cytotoxicity. For this reason, it would be interesting to analyze whether Myolg has a similar function during NK-cell lipid rafts mobilization during synapsis and in other functions, where lipid microdomains mobilization is also required. Besides, it has been reported that in the absence of Myolg, lymphocytes present a lower membrane tension, which decreases their ability to generate membrane structures $(64,83)$. In addition to regulating the elasticity and stiffness of the membrane, membrane tension can generate morphological changes through the PLD2mTORC2 signaling pathway $(82,105)$. Since, Myolg and Myolf are located adjacent to the plasma membrane, co-localizing with cortical actin $(63,67)$. So then, it would be interesting to know if Myolg and Myolf intervene in the mechano-transduction process by NK cells as described in other cell types.

\section{DISCUSSION}

To date, there is no information about the role of class I myosins in NK cells functions. However, evidence in other cell lineages suggests that Myolg and Myolf could participate by regulating different NK cell functions such as cytokines release, synapse formation, granule mobilization, and migration. The functional defects described by the absence of Myolg and Myolf could similarly affect NK cells, causing increased susceptibility to viral infections and tumor development. Due to the tail's structural differences, the mechanism by which Myolg and Myolf may regulate these processes will not be the same. Since Myolf has a TH2 and an SH3 domain, the functions of Myolf could depend on proteinprotein interactions $(85,106)$, while the function of Myolg could depend on its interaction with phosphoinositides present in membranes and vesicles (85). The function of class I myosins seems to depend on cell activation but also cell lineage. Therefore, it would be interesting to study these proteins in the context of NK cells and other ILCs subpopulations. To date, there is no information available about myosin mutations in humans that could be associated with NK cell function. However, the use of 


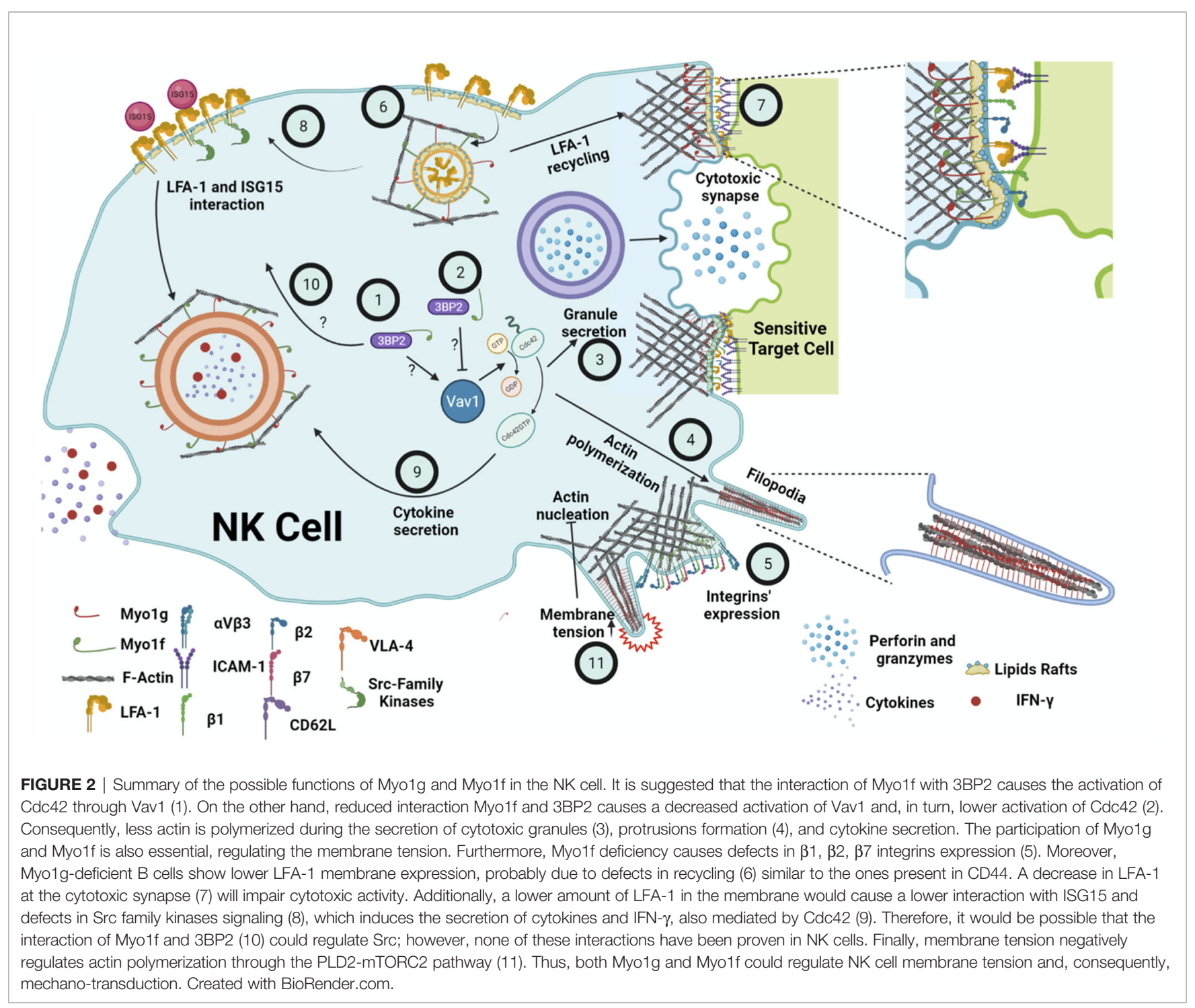

murine models or cell lines deficient or overexpressing Myolg and Myolf could reveal the role of these myosins in NK cells and other ILCs subpopulations. Figure 2 summarizes what we believe may be the participation of Myolg and Myolf in the functions of NK cells.

\section{AUTHOR CONTRIBUTIONS}

DC-Z, CM-R, IM-V, and LS-A wrote the manuscript with contributions by all authors. DC-Z, CM-R, and IM-V designed

\section{REFERENCES}

1. Artis D, Spits H. The Biology of Innate Lymphoid Cells. Nature (2015) 517:293-301. doi: 10.1038/nature14189

2. Constantinides MG, McDonald BD, Verhoef PA, Bendelac A. A Committed Precursor to Innate Lymphoid Cells. Nature (2014) 508:397-401. doi: $10.1038 /$ nature13047 at the heat map under LS-A supervision. DC-Z, CM-R, and $\mathrm{IM}-\mathrm{V}$ designed and drew the illustration under LS-A supervision. All authors contributed to the article and approved the submitted version.

\section{FUNDING}

DCZ, CEMR and IMV were supported by CONACyT schoolarships 632703, 780860 and 780744 . 
T Cells Potentiates Type 2 Immunity and Promotes Parasitic Helminth Expulsion. Immunity (2014) 41:283-95. doi: 10.1016/j.immuni.2014.06.016

6. Monticelli L, Sonnenberg GF, Abt MC, Alenghat T, Ziegler CGK, Doering TA, et al. Innate Lymphoid Cells Promote Lung-Tissue Homeostasis After Infection With Influenza Virus. Nat Immunol (2011) 12:1045-54. doi: $10.1038 /$ ni.2131

7. Crinier A, Narni-Mancinelli E, Ugolini S, Vivier E. SnapShot: Natural Killer Cells. Cell (2020) 180:1280-1280.e1. doi: 10.1016/j.cell.2020.02.029

8. Ebbo M, Crinier A, Vély F, Vivier E. Innate Lymphoid Cells: Major Players in Inflammatory Diseases. Nat Rev Immunol (2017) 17:665-78. doi: 10.1038/nri.2017.86

9. Diefenbach A. Innate Lymphoid Cells in the Defense Against Infections. Eur J Microbiol Immunol (Bp) (2013) 3:143-51. doi: 10.1556/EuJMI.3.2013.3.1

10. Vivier E, Artis D, Colonna M, Diefenbach A, Di Santo JP, Eberl G, et al. Innate Lymphoid Cells: 10 Years on. Cell (2018) 174:1054-66. doi: 10.1016/ j.cell.2018.07.017

11. Wang S, Xia P, Chen Y, Qu Y, Xiong Z, Ye B, et al. Regulatory Innate Lymphoid Cells Control Innate Intestinal Inflammation. Cell (2017) 171:201-216.e18. doi: 10.1016/j.cell.2017.07.027

12. Scharschmidt TC. ILCregs: The New Kid in Class. Sci Transl Med (2017) 9: eaao6121. doi: 10.1126/scitranslmed.aao6121

13. Yu J, Li Y, Pan Y, Liu Y, Xing H, Xie X, et al. Deficient Regulatory Innate Lymphoid Cells and Differential Expression of miRNAs in Acute Myeloid Leukemia Quantified by Next Generation Sequence. Cancer Manage Res (2019) 11:10969-82. doi: 10.2147/CMAR.S234327

14. Spits H, Artis D, Colonna M, Diefenbach A, Di Santo JP, Eberl G, et al. Innate Lymphoid Cells - A Proposal for Uniform Nomenclature. Nat Rev Immunol (2013) 13:145-9. doi: 10.1038/nri3365

15. Panda SK, Colonna M. Innate Lymphoid Cells in Mucosal Immunity. Front Immunol (2019) 10:861. doi: 10.3389/fimmu.2019.00861

16. Mujal AM, Delconte RB, Sun JC. Natural Killer Cells: From Innate to Adaptive Features. Annu Rev Immunol (2021) 39:417-47. doi: 10.1146/ annurev-immunol-101819-074948

17. Moretta L, Bottino C, Pende D, Mingari MC, Biassoni R, Moretta A, et al. Human Natural Killer Cells: Their Origin, Receptors and Function. Eur J Immunol (2002) 32:1205-11. doi: 10.1002/1521-4141(200205)32:5<1205:: AID-IMMU1205 $>3.0$. CO;2-Y

18. Lanier LL. Natural Killer Cell Receptor Signaling. Curr Opin Immunol (2003) 15:308-14. doi: 10.1016/S0952-7915(03)00039-6

19. Moretta L, Moretta A. Unravelling Natural Killer Cell Function: Triggering and Inhibitory Human NK Receptors. EMBO J (2004) 23:255-9. doi: 10.1038/sj.emboj.7600019

20. Lanier LL, Cortiss BC, Wu J, Leong C, Phillips JH. Immunoreceptor DAP12 Bearing a Tyrosine-Based Activation Motif Is Involved in Activating NK Cells. Nature (1998) 391:703-7. doi: 10.1038/35642

21. Latour S, Roncagalli R, Chen R, Bakinowski M, Shi X, Schwartzberg PL, et al. Binding of SAP SH2 Domain to FynT SH3 Domain Reveals a Novel Mechanism of Receptor Signalling in Immune Regulation. Nat Cell Biol (2003) 5:149-54. doi: 10.1038/ncb919

22. Dong Z, Davidson D, Pérez-Quintero LA, Kurosaki T, Swat W, Veillette A, et al. The Adaptor SAP Controls NK Cell Activation by Regulating the Enzymes Vav-1 and SHIP-1 and by Enhancing Conjugates With Target Cells. Immunity (2012) 36:974-85. doi: 10.1016/j.immuni.2012.03.023

23. Billadeau DD, Upshaw JL, Schoon RA, Dick CJ, Leibson PJ. NKG2D-DAP10 Triggers Human NK Cell-Mediated Killing via a Syk-Independent Regulatory Pathway. Nat Immunol (2003) 4:557-64. doi: 10.1038/ni929

24. Gilfillan S, Ho EL, Cella M, Yokohama WM, Colonna M. NKG2D Recriuts Two Distinct Adapters to Trigger NK Cell Activation and Costimulation. Nat Immunol (2002) 3:1150-5. doi: 10.1038/ni857

25. Upshaw JL, Arneson LN, Schoon RA, Dick CJ, Billadeau DD, Leibson PJ, et al. NKG2D-Mediated Signaling Requires a DAP10-Bound Grb2-Vav1 Intermediate and Phosphatidylinositol-3-Kinase in Human Natural Killer Cells. Nat Immunol (2006) 7:524-32. doi: 10.1038/ni1325

26. Graham DB, Cella M, Giurisato E, Fujikawa K, Miletic AV, Kloeppel T, et al. Vav1 Controls DAP10-Mediated Natural Cytotoxicity by Regulating Actin and Microtubule Dynamics. J Immunol (2006) 177:2349-55. doi: 10.4049/ jimmunol.177.4.2349
27. Colucci F, Rosmaraki E, Bregenholt S, Samson SI, Di Bartolo V, Turner M, et al. Functional Dichotomy in Natural Killer Cell Signaling: Vav1Dependent and -Independent Mechanisms. J Exp Med (2001) 193:141324. doi: $10.1084 / \mathrm{jem} .193 .12 .1413$

28. Kim HS, Das A, Gross CC, Bryceson YT, Long EO. Synergistic Signals for Natural Cytotoxicity Are Required to Overcome Inhibition by C-Cbl Ubiquitin Ligase. Immunity (2010) 32:175-86. doi: 10.1016/ j.immuni.2010.02.004

29. Tapon N, Hall A. Rho, Rac and Cdc42 GTPases Regulate the Organization of the Actin Cytoskeleton. Curr Opin Cell Biol (1997) 9:86-92. doi: 10.1016/ S0955-0674(97)80156-1

30. Sun JC, Beilke JN, Lanier LL. Adaptive Immune Features of Natural Killer Cells. Nature (2009) 457:557-61. doi: 10.1038/nature07665

31. Vivier E, Tomasello E, Baratin M, Walzer T, Ugolini S. Functions of Natural Killer Cells. Nat Immunol (2008) 9:503-10. doi: 10.1038/ni1582

32. Hayakawa Y, Smyth MJ. CD27 Dissects Mature NK Cells Into Two Subsets With Distinct Responsiveness and Migratory Capacity. J Immunol (2006) 176:1517-24. doi: 10.4049/jimmunol.176.3.1517

33. Cooper MA, Fehniger TA, Caligiuri MA. The Biology of Human Natural Killer-Cell Subsets. Trends Immunol (2001) 22:633-40. doi: 10.1016/S14714906(01)02060-9

34. Mavilio D, Lombardo G, Benjamin J, Kim D, Follman D, Marcenaro E, et al. Characterization of CD56-/CD16+ Natural Killer (NK) Cells: A Highly Dysfunctional NK Subset Expanded in HIV-Infected Viremic Individuals. Proc Natl Acad Sci USA (2005) 102:2886-91. doi: 10.1073/pnas.0409872102

35. Smyth MJ, Cretney E, Kelly JM, Westwood JA, Street SEA, Yagita H, et al. Activation of NK Cell Cytotoxicity. Mol Immunol (2005) 42:501-10. doi: 10.1016/j.molimm.2004.07.034

36. Stinchcombe JC, Griffiths GM. Secretory Mechanisms in Cell-Mediated Cytotoxicity. Annu Rev Cell Dev Biol (2007) 23:495-517. doi: 10.1146/ annurev.cellbio.23.090506.123521

37. Prager I, Liesche C, Van Ooijen H, Urlaub D, Verron Q, Sandström N, et al. NK Cells Switch From Granzyme B to Death Receptor-Mediated Cytotoxicity During Serial Killing. J Exp Med (2019) 216:2113-27. doi: 10.1084/jem.20181454

38. Urlaub D, Höfer K, Müller M-L, Watzl C. LFA-1 Activation in NK Cells and Their Subsets: Influence of Receptors, Maturation, and Cytokine Stimulation. J Immunol (2017) 198:1944-51. doi: 10.4049/ jimmunol.1601004

39. Long EO. Negative Signaling by Inhibitory Receptors: The NK Cell Paradigm. Immunol Rev (2008) 224:70-84. doi: 10.1111/j.1600065X.2008.00660.x

40. Abeyweera TP, Merino E, Huse M. Inhibitory Signaling Blocks Activating Receptor Clustering and Induces Cytoskeletal Retraction in Natural Killer Cells. J Cell Biol (2011) 192:675-90. doi: 10.1083/ jcb. 201009135

41. Schenkel AR, Kingry LC, Slayden RA. The Ly49 Gene Family. A Brief Guide to the Nomenclature, Genetics, and Role in Intracellular Infection. Front Immunol (2013) 4:90. doi: 10.3389/fimmu.2013.00090

42. Santoni G, Amantini C, Santoni M, Maggi F, Morelli MB, Santoni A. Mechanosensation and Mechanotransduction in Natural Killer Cells. Front Immunol (2021) 12:688918. doi: 10.3389/fimmu.2021.688918

43. Bryceson YT, March ME, Ljunggren HG, Long EO. Activation, Coactivation, and Costimulation of Resting Human Natural Killer Cells. Immunol Rev (2006) 214:73-91. doi: 10.1111/j.1600-065X.2006.00457.x

44. Dogra P, Rancan C, Ma W, Toth M, Senda T, Carpenter DJ, et al. Tissue Determinants of Human NK Cell Development, Function, and Residence. Cell (2020) 180:749-763.e13. doi: 10.1016/j.cell.2020.01.022

45. Cooper MA, Fehniger TA, Turner SC, Chen KS, Ghaheri BA, Ghayur T, et al. Human Natural Killer Cells: A Unique Innate Immunoregulatory Role for the CD56bright Subset. Blood (2001) 97:3146-51. doi: 10.1182/ blood.V97.10.3146

46. Titus MA. Myosin-Driven Intracellular Transport. Cold Spring Harb Perspect Biol (2018) 10:a021972. doi: 10.1101/cshperspect.a021972

47. Hammer JA, Sellers JR. Walking to Work: Roles for Class V Myosins as Cargo Transporters. Nat Rev Mol Cell Biol (2012) 13:13-26. doi: 10.1038/ nrm3248 
48. Kee AJ, Yang L, Lucas CA, Greenberg MJ, Martel N, Leong GM, et al. An Actin Filament Population Defined by the Tropomyosin Tpm3.1 Regulates Glucose Uptake. Traffic (2015) 16:691-711. doi: 10.1111/tra.12282

49. de Jonge JJ, Batters C, O'Loughlin T, Arden SD, Buss F. The MYO6 Interactome: Selective Motor-Cargo Complexes for Diverse Cellular Processes. FEBS Lett (2019) 593:1494-507. doi: 10.1002/1873-3468.13486

50. Rayment I, Holden HM. The Three-Dimensional Structure of a Molecular Motor. Trends Biochem Sci (1994) 19:129-34. doi: 10.1016/0968-0004(94) 90206-2

51. Girón-Pérez DA, Piedra-Quintero ZL, Santos-Argumedo L. Class I Myosins: Highly Versatile Proteins With Specific Functions in the Immune System. J Leukoc Biol (2019) 105:973-81. doi: 10.1002/JLB.1MR0918-350RRR

52. Odronitz F, Kollmar M. Drawing the Tree of Eukaryotic Life Based on the Analysis of 2,269 Manually Annotated Myosins From 328 Species. Genome Biol (2007) 8:R196. doi: 10.1186/gb-2007-8-9-r196

53. Berg JS, Powell BC, Cheney RE. A Millennial Myosin Census. Mol Biol Cell (2001) 12:780-94. doi: 10.1091/mbc.12.4.780

54. Heissler SM, Sellers JR. Kinetic Adaptations of Myosins for Their Diverse Cellular Functions. Traffic (2016) 17:839-59. doi: 10.1111/tra.12388

55. Pasha SN, Meenakshi I, Sowdhamini R. Revisiting Myosin Families Through Large-Scale Sequence Searches Leads to the Discovery of New Myosins. Evol Bioinforma (2016) 12:201-11. doi: 10.4137/EBO.S39880

56. Sellers JR. Myosins: A Diverse Superfamily. Biochim Biophys Acta-Mol Cell Res (2000) 1496:3-22. doi: 10.1016/S0167-4889(00)00005-7

57. Krendel M, Mooseker MS. Myosins: Tails (and Heads) of Functional Diversity. Physiology (2005) 20:239-51. doi: 10.1152/physiol.00014.2005

58. McIntosh BB, Ostap EM. Myosin-I Molecular Motors at a Glance. J Cell Sci (2016) 129:2689-95. doi: 10.1242/jcs.186403

59. Olety B, Wälte M, Honnert U, Schillers H, Bähler M. Myosin 1g (Myo1G) Is a Haematopoietic Specific Myosin That Localises to the Plasma Membrane and Regulates Cell Elasticity. FEBS Lett (2010) 584:493-9. doi: 10.1016/ j.febslet.2009.11.096

60. Maravillas-Montero JL, Santos-Argumedo L. The Myosin Family: Unconventional Roles of Actin-Dependent Molecular Motors in Immune Cells. J Leukoc Biol (2012) 91:35-46. doi: 10.1189/jlb.0711335

61. Patino-Lopez G, Aravind L, Dong X, Kruhlak MJ, Ostap EM, Shaw S, et al. Myosin 1G Is an Abundant Class I Myosin in Lymphocytes Whose Localization at the Plasma Membrane Depends on Its Ancient Divergent Pleckstrin Homology (PH) Domain (Myo1PH). J Biol Chem (2010) 285:8675-86. doi: 10.1074/jbc.M109.086959

62. Santos-Argumedo L, Maravillas-Montero JL, López-Ortega O. Class I Myosins in B-Cell Physiology: Functions in Spreading, Immune Synapses, Motility, and Vesicular Traffic. Immunol Rev (2013) 256:190-202. doi: 10.1111/imr.12105

63. Maravillas-Montero JL, López-Ortega O, Patiño-López G, Santos-Argumedo L. Myosin 1g Regulates Cytoskeleton Plasticity, Cell Migration, Exocytosis, and Endocytosis in B Lymphocytes. Eur J Immunol (2014) 44:877-86. doi: 10.1002/eji.201343873

64. Gérard A, Patino-Lopez G, Beemiller P, Nambiar R, Ben-Aissa K, Liu Y, et al. Detection of Rare Antigen-Presenting Cells Through T Cell-Intrinsic Meandering Motility, Mediated by Myolg. Cell (2014) 158:492-505. doi: 10.1016/j.cell.2014.05.044

65. Cruz-Zárate D, López-Ortega O, Girón-Pérez DA, Gonzalez-Suarez AM, García-Cordero JL, Schnoor M, et al. Myolg Is Required for Efficient Adhesion and Migration of Activated B Lymphocytes to Inguinal Lymph Nodes. Sci Rep (2021) 11:7197. doi: 10.1038/s41598-021-85477-y

66. López-Ortega O, Santos-Argumedo L. Myosin 1g Contributes to CD44 Adhesion Protein and Lipid Rafts Recycling and Controls CD44 Capping and Cell Migration in B Lymphocytes. Front Immunol (2017) 8:1731. doi: 10.3389/fimmu.2017.01731

67. Kim SV, Mehal WZ, Dong X, Heinrich V, Pypaert M, Mellman I, et al. Modulation of Cell Adhesion and Motility in the Immune System by Myolf. Sci (80- ) (2006) 314:136-9. doi: 10.1126/science.1131920

68. Salvermoser M, Pick R, Weckbach LT, Zehrer A, Löhr P, Drechsler M, et al. Myosin If Is Specifically Required for Neutrophil Migration in 3D Environments During Acute Inflammation. Blood (2018) 131:1887-98. doi: 10.1182/blood-2017-10-811851
69. Navinés-Ferrer A, Ainsua-Enrich E, Serrano-Candelas E, Sayós J, Martin M. Myo1F, an Unconventional Long-Tailed Myosin, Is a New Partner for the Adaptor 3BP2 Involved in Mast Cell Migration. Front Immunol (2019) 10:1058. doi: 10.3389/fimmu.2019.01058

70. Piedra-Quintero ZL, Serrano C, Villegas-Sepúlveda N, Maravillas-Montero JL, Romero-Ramírez S, Shibayama M, et al. Myosin 1F Regulates M1Polarization by Stimulating Intercellular Adhesion in Macrophages. Front Immunol (2019) 10:3118. doi: 10.3389/fimmu.2018.03118

71. Riley JL, Mao M, Kobayashi S, Biery M, Burchard J, Cavet G, et al. Modulation of TCR-Induced Transcriptional Profiles by Ligation of CD28, ICOS, and CTLA-4 Receptors. Proc Natl Acad Sci USA (2002) 99:11790-5. doi: 10.1073/pnas.162359999

72. Navinés-Ferrer A, Ainsua-Enrich E, Serrano-Candelas E, Proaño-Pérez E, Muñoz-Cano R, Gastaminza G, et al. MYO1F Regulates IgE and MRGPRX2Dependent Mast Cell Exocytosis. J Immunol (2021) 206:2277-89. doi: 10.4049/jimmunol.2001211

73. Foucault I, Le Bras S, Charvet C, Moon C, Altman A, Deckert M, et al. The Adaptor Protein 3BP2 Associates With VAV Guanine Nucleotide Exchange Factors to Regulate NFAT Activation by the B-Cell Antigen Receptor. Blood (2005) 105:1106-13. doi: 10.1182/blood-2003-08-2965

74. Heng TSP, Painter MW, Elpek K, Lukacs-Kornek V, Mauermann N, Turley SJ, et al. The Immunological Genome Project: Networks of Gene Expression in Immune Cells. Nat Immunol (2008) 9:1091-4. doi: 10.1038/ ni1008-1091

75. Monaco G, Lee B, Xu W, Mustafah S, Hwang YY, Carré C, et al. RNA-Seq Signatures Normalized by mRNA Abundance Allow Absolute Deconvolution of Human Immune Cell Types. Cell Rep (2019) 26:16271640.e7. doi: 10.1016/j.celrep.2019.01.041

76. Schmiedel BJ, Singh D, Madrigal A, Valdovino-Gonzalez AG, White BM, Zapardiel-Gonzalo J, et al. Impact of Genetic Polymorphisms on Human Immune Cell Gene Expression. Cell (2018) 175:1701-15.e16. doi: 10.1016/ j.cell.2018.10.022

77. Yang C, Siebert JR, Burns R, Gerbec ZJ, Bonacci B, Rymaszewski A, et al. Heterogeneity of Human Bone Marrow and Blood Natural Killer Cells Defined by Single-Cell Transcriptome. Nat Commun (2019) 10:3931. doi: 10.1038/s41467-019-11947-7

78. Dadi S, Chhangawala S, Whitlock BM, Franklin RA, Luo SA, Oh A, et al. Cancer Immunosurveillance by Tissue-Resident Innate Lymphoid Cells and Innate-Like T Cells. Cell (2016) 164:365-77. doi: 10.1016/j.cell.2016.01.002

79. Orange JS. The Lytic NK Cell Immunological Synapse and Sequential Steps in Its Formation. Adv Exp Med Biol (2007) 601:225-33. doi: 10.1007/978-0387-72005-0_23

80. Wurzer H, Hoffmann C, Al Absi A, Thomas C. Actin Cytoskeleton Straddling the Immunological Synapse Between Cytotoxic Lymphocytes and Cancer Cells. Cells (2019) 8:463. doi: 10.3390/cells8050463

81. Batchelder EL, Hollopeter G, Campillo C, Mezanges X, Jorgensen EM, Nassoy P, et al. Membrane Tension Regulates Motility by Controlling Lamellipodium Organization. Proc Natl Acad Sci USA (2011) 108:1142934. doi: $10.1073 /$ pnas. 1010481108

82. Diz-Muñoz A, Thurley K, Chintamen S, Altschuler SJ, Wu LF, Fletcher DA, et al. Membrane Tension Acts Through PLD2 and Mtorc2 to Limit Actin Network Assembly During Neutrophil Migration. PloS Biol (2016) 14: e1002474. doi: 10.1371/journal.pbio.1002474

83. López-Ortega O, Ovalle-García E, Ortega-Blake I, Antillón A, ChávezMunguía B, Patiño-López G, et al. Myolg Is an Active Player in Maintaining Cell Stiffness in B-Lymphocytes. Cytoskeleton (2016) 73:25868. doi: $10.1002 / \mathrm{cm} .21299$

84. Wenzel J, Ouderkirk JL, Krendel M, Lang R. Class I Myosin Myole Regulates TLR4-Triggered Macrophage Spreading, Chemokine Release, and Antigen Presentation via MHC Class II. Eur J Immunol (2015) 45:225-37. doi: 10.1002/eji.201444698

85. Girón-Pérez DA, Vadillo E, Schnoor M, Santos-Argumedo L. Myole Modulates the Recruitment of Activated B Cells to Inguinal Lymph Nodes. J Cell Sci (2020) 133:jcs235275. doi: 10.1242/jcs.235275

86. Gismondi A, Santoni A. Migration of NK Cells. In: Lymphocyte Trafficking in Health and Disease. Basel: Birkhäuser (2006). p. 95-112. doi: 10.1007/37643-7442-x_6 
87. Moore KL, Thompson LF. P-Selectin (CD62) Binds to Subpopulations of Human Memory T Lymphocytes and Natural Killer Cells. Biochem Biophys Res Commun (1992) 186:173-81. doi: 10.1016/S0006-291X(05)80790-9

88. Casilli F, Bianchini A, Gloaguen I, Biordi L, Alesse E, Festuccia C, et al. Inhibition of Interleukin-8 (CXCL8/IL-8) Responses by Repertaxin, a New Inhibitor of the Chemokine Receptors CXCR1 and CXCR2. Biochem Pharmacol (2005) 69:385-94. doi: 10.1016/j.bcp.2004.10.007

89. Campbell JJ, Qin S, Unutmaz D, Soler D, Murphy KE, Hodge MR, et al. Unique Subpopulations of CD56 + NK and NK-T Peripheral Blood Lymphocytes Identified by Chemokine Receptor Expression Repertoire. J Immunol (2001) 166:6477-82. doi: 10.4049/jimmunol.166.11.6477

90. Nobes CD, Hall A. Rho, Rac, and Cdc42 GTPases Regulate the Assembly of Multimolecular Focal Complexes Associated With Actin Stress Fibers, Lamellipodia, and Filopodia. Cell (1995) 81:53-62. doi: 10.1016/0092-8674 (95)90370-4

91. El Masri R, Delon J. RHO GTPases: From New Partners to Complex Immune Syndromes. Nat Rev Immunol (2021) 21(8):499-513. doi: 10.1038/s41577-021-00500-7

92. Gross CC, Brzostowski JA, Liu D, Long EO. Tethering of Intercellular Adhesion Molecule on Target Cells Is Required for LFA-1-Dependent NK Cell Adhesion and Granule Polarization. J Immunol (2010) 185:2918-26. doi: 10.4049/jimmunol.1000761

93. Helander TS, Timonen T. Adhesion in NK Cell Function. In: Current Topics in Microbiology and Immunology, vol. 230. Berlin, Heidelberg: Springer. (1998). p. 89-99.

94. Colucci F, Caligiuri MA, Di Santo JP. What Does It Take to Make a Natural Killer? Nat Rev Immunol (2003) 3:413-25. doi: 10.1038/nri1088

95. Cullen SP, Martin SJ. Mechanisms of Granule-Dependent Killing. Cell Death Differ (2008) 15:251-62. doi: 10.1038/sj.cdd.4402244

96. Mentlik AN, Sanborn KB, Holzbaur EL, Orange JS. Rapid Lytic Granule Convergence to the MTOC in Natural Killer Cells Is Dependent on Dynein But Not Cytolytic Commitment. Mol Biol Cell (2010) 21:2241-56. doi: 10.1091/mbc.e09-11-0930

97. Prager I, Watzl C. Mechanisms of Natural Killer Cell-Mediated Cellular Cytotoxicity. J Leukoc Biol (2019) 105:1319-29. doi: 10.1002/JLB.MR0718-269R

98. De Saint Basile G, Ménasché G, Fischer A. Molecular Mechanisms of Biogenesis and Exocytosis of Cytotoxic Granules. Nat Rev Immunol (2010) 10:568-79. doi: 10.1038/nri2803

99. Rodriguez MR, Monte K, Thackray LB, Lenschow DJ. ISG15 Functions as an Interferon-Mediated Antiviral Effector Early in the Murine Norovirus Life Cycle. J Virol (2014) 88:9277-86. doi: 10.1128/JVI.01422-14
100. Blomstrom DC, Fahey D, Kutny R, Korant BD, Knight E. Molecular Characterization of the Interferon-Induced $15-\mathrm{kDa}$ Protein. Molecular Cloning and Nucleotide and Amino Acid Sequence. J Biol Chem (1986) 261:8811-6. doi: 10.1016/S0021-9258(19)84453-8

101. Swaim CD, Scott AF, Canadeo LA, Huibregtse JM. Extracellular ISG15 Signals Cytokine Secretion Through the LFA-1 Integrin Receptor. Mol Cell (2017) 68:581-590.e5. doi: 10.1016/j.molcel.2017.10.003

102. Morgan A. Exocytosis. Essays Biochem (1995) 30:77-95. doi: 10.1146/ annurev.physiol.52.1.607

103. Ponta H, Sherman L, Herrlich PA. CD44: From Adhesion Molecules to Signalling Regulators. Nat Rev Mol Cell Biol (2003) 4:33-45. doi: 10.1038/ nrm1004

104. Fassett MS, Davis DM, Valter MM, Cohen GB, Strominger JL. Signaling at the Inhibitory Natural Killer Cell Immune Synapse Regulates Lipid Raft Polarization But Not Class I MHC Clustering. Proc Natl Acad Sci USA (2001) 98:14547-52. doi: 10.1073/pnas.211563598

105. Böttcher RT, Fässler R. Membrane Tension Drives Ligand-Independent Integrin Signaling. EMBO J (2014) 33:2439-41. doi: 10.15252/ embj.201489886

106. Liu D, Bryceson YT, Meckel T, Vasiliver-Shamis G, Dustin L, Long EO, et al. Integrin-Dependent Organization and Bidirectional Vesicular Traffic at Cytotoxic Immune Synapses. Immunity (2009) 31:99-109. doi: 10.1016/ j.immuni.2009.05.009

Conflict of Interest: The authors declare that the research was conducted in the absence of any commercial or financial relationships that could be construed as a potential conflict of interest.

Publisher's Note: All claims expressed in this article are solely those of the authors and do not necessarily represent those of their affiliated organizations, or those of the publisher, the editors and the reviewers. Any product that may be evaluated in this article, or claim that may be made by its manufacturer, is not guaranteed or endorsed by the publisher.

Copyright (C) 2021 Cruz-Zárate, Miguel-Rodríguez, Martínez-Vargas and SantosArgumedo. This is an open-access article distributed under the terms of the Creative Commons Attribution License (CC BY). The use, distribution or reproduction in other forums is permitted, provided the original author(s) and the copyright owner(s) are credited and that the original publication in this journal is cited, in accordance with accepted academic practice. No use, distribution or reproduction is permitted which does not comply with these terms. 